\title{
Plant science's human factor
}

\section{People have learned much from being fed, clothed, sheltered and medicated by plants over millennia. Such traditional knowledge can yield practical discoveries and an understanding of our societies.}

Few studies in the plant sciences directly consider the interactions between humanity and the plant kingdom. At Nature Plants we believe that any attempt to provide a picture of our growing understanding of plants must include the societal aspects of that endeavour. For example, in this issue we have two studies with a social focus (see Letter by S. Mourtzinis et al. and Article by C. L. Quave and A. Pieroni).

This interface of anthropology and botany, or 'ethnobotany', is a wide-ranging area employing techniques from many disciplines. Those who work in ethnobotany describe its appeal as giving their studies a human dimension. Ulysses Paulino de Albuquerque, of the Universidade Federal Rural de Pernambuco in Brazil, is typical, "Even when operating in other fields, I always missed the 'human being"' he says. "Initially, I was more eager to describe the use of plants by people, today I am concerned to understand the many factors that modulate the mutual relations between people and plants."

The term ethnobotany was coined in 1896 by the American botanist John W. Harshberger, although the name remains quite fluid with some researchers favouring 'ethnobiology' and others 'economic botany'. For much of its history ethnobotany was concerned with documenting economic or medicinal use of plants. However in the late 1950s Harold C. Conklin's studies of plant names in the Phillipines inspired the use of ethnobotany to investigate traditional societies through their usage of plants.

By the 1990s the focus was back on economically useful botany, particularly as potential leads for the pharmaceutical industry. In his influential 1992 book The Primary Source: Tropical Forests and our Future, British environmentalist Norman Myers described forests as "vast pharmaceutical factories". But over the next decade that promise of a 'cure for cancer' in the tropical forests remained largely unfulfilled as illustrated by the case of Shaman pharmaceuticals.

Shaman was set up by Californian entrepreneur Lisa Conte in 1989 and became focussed on exploiting the anti-diarrheal properties of the 'dragon's blood' tree, Croton lechleri, of South America. There were promising results but the time and expense of performing phase III trials forced Shaman to give up seeking FDA approval for their drug, crofelemer, in early 1999. The company went into bankruptcy in 2001. This failure prompted The Economist to declare an end to the ethnobotanical approach of converting "old-wives' tales into drugs" (Shaman loses its magic. The Economist 18 February 1999).

This pronouncement may have been premature. In 2012 Napo Pharmaceuticals, a company also set up by Conte, secured FDA approval for crofelemer as an antidiarrheal drug for patients with HIV/AIDS and it is now being used under the trade name Fulyzaq. However, concerns over the exploitation of the indigenous holders of traditional knowledge, 'biopiracy' if you will, mean that things are done differently now.

In Australia the Chuulangun Aboriginal Corporation of Cape York, Queensland is working with scientists to investigate the pharmacology of plant species used as traditional medicines. Susan Semple, a senior research fellow at the University of South Australia, points out that this project was initiated by the community. "They came to us and they are the drivers of the collaboration," she says. Current 'custodians' of traditional knowledge, and ancestors from whom it is thought to have originated, are made authors on papers and patents. Also, all the plant materials are grown on the aboriginal homelands and 'pass through the hands' of the community to ensure their efficacy.

The project is not just about using the traditional knowledge of the aboriginal community for their economic benefit, it also aims to record that knowledge so that it can be preserved and transferred among families living on the homelands. For this, the skills of an 'environmental anthropologist' (another alternative to ethnobotanist) have been invaluable. So far the collaboration has produced a joint patent between the Chuulangun Aboriginal Corporation and the University of South Australia for an antiinflammatory compound from the hop-bush, Dodonaea polyandra. The resulting press coverage has encouraged other community groups to approach the researchers to set up similar projects.

Giving proper recognition for the traditional knowledge, acquired over thousands of years, that indigenous communities bring will require a global instrument to protect their intellectual property. One step in that direction is the Nagoya Protocol on Access and Benefit Sharing (www.cbd.int/abs), signed in 2011 and adopted by over fifty states including the European Union. However, it falls short of universality as many countries are absent including China, Russia and the USA.

Ethnobotany goes beyond identifying active compounds from 'exotic' plants. The traditional knowledge of any community is constantly changing, being gained as well as lost. Studying such changes in a western, developed country - for example research from the University of Kent on suburban gardeners and allotment holders - is as important as in inaccessible rainforests. What all such ethnobotanical studies have in common is an emphasis on place, "If you are not in the field," says Manuel Pardo de Santayana, from the University of Madrid, "you will never understand the people; they change you."

Ethnobotany was once an umbrella term for a number disconnected research areas, but that is changing. "All the branches are coming back together," says Rainer Bussman, of the Missouri Botanical Gardens, "it is not a science that can look at individual parts; it needs an holistic approach." This causes problems of its own. Funding agencies must think beyond the comfort zones of their core subjects and disparate specialists need to talk efficiently with each other. "Today, it is very difficult to compare data from different papers because of differences in approaches and theoretical backgrounds, data collection methods and research questions," complains d'Aberquerque "we need a 'theoretical framework' that addresses and integrates this diversity."

At its heart, ethnobotany is about the constantly changing relationship between ourselves and our environment. The sources of that change can be very modern: migration, climate change, habitat loss and our drive to exploit the world in which we live. For all its history, ethnobotany is a very modern fusion of social, physical and life sciences; a multifaceted discipline with an exciting future. 